\title{
Evaluation of the Impact of Queue Trucks with Navigation Alerts Using Connected Vehicle Data
}

\author{
Rahul Suryakant Sakhare1, Jairaj C. Desai', Justin Mahlberg', Jijo K. Mathew ${ }^{1}$, Woosung Kim¹, \\ Howell Li' ${ }^{1}$ John D. McGregor ${ }^{2}$, Darcy M. Bullock ${ }^{1}$ \\ ${ }^{1}$ Purdue University, West Lafayette, USA \\ ${ }^{2}$ Indiana Department of Transportation, Indianapolis, USA \\ Email: rsakhare@purdue.edu, desaij@purdue.edu,jmahlber@purdue.edu,kjijo@purdue.edu, kim898@purdue.edu, \\ howell-li@purdue.edu,jmcgregor@indot.in.gov, darcy@purdue.edu
}

How to cite this paper: Sakhare, R.S., Desai, J.C., Mahlberg, J., Mathew, J.K., Kim, W., Li, H., McGregor, J.D. and Bullock, D.M. (2021) Evaluation of the Impact of Queue Trucks with Navigation Alerts Using Connected Vehicle Data. Journal of Transportation Technologies, 11, 561-576. https://doi.org/10.4236/jtts.2021.114035

Received: August 7, 2021

Accepted: September 3, 2021

Published: September 6, 2021

Copyright $\odot 2021$ by author(s) and Scientific Research Publishing Inc. This work is licensed under the Creative Commons Attribution International License (CC BY 4.0).

http://creativecommons.org/licenses/by/4.0/

\begin{abstract}
Back of queue crashes on Interstates are a major concern for all state transportation departments. In 2020, Indiana DOT begin deploying queue warning trucks with message boards, flashers and digital alerts that could be transmitted to navigation systems such as Waze. This study reports on the deployment and impact evaluation of digital alerts on motorist's assistance patrols and 19 Queue trucks in Indiana. The motorist assistance patrol evaluation is provided qualitatively. A novel analysis of queue warning trucks equipped with digital alerts was conducted during the months of May-July in 2021 using connected vehicle data. This new data set reports locations of anonymous hard-braking events from connected vehicles on the Interstate. Hard-braking events were tabulated for when queueing occurred with and without the presence of a queue warning truck. Approximately 370 hours of queueing with queue trucks present and 58 hours of queueing without queue trucks present were evaluated. Hard-braking events were found to decrease approximately $80 \%$ when queue warning trucks were used to alert motorists of impending queues.
\end{abstract}

\section{Keywords}

Queue Trucks, Navigation Alerts, Connected Vehicle Data, Hard-Braking Events, Motorists' Safety

\section{Motivation}

Back of queue crashes are an emerging national problem and several states are exploring or deploying queue warning trucks to increase the alertness of drivers approaching stopped traffic on the interstate [1] [2]. The motivation of this pa- 
per is to report on the evaluation of the deployment of queue warning trucks in Indiana to alert motorists to stopped traffic using a combination of signs, lights, message boards and digital navigation alerts.

\section{Introduction}

Identifying opportunities for continuous improvement in roadway safety is a priority for all transportation agencies. Crash incidents on interstates, maintenance activities or ongoing work zone activities often result in slow traffic and/or forming queues. The boundary between free-flow conditions and queue traffic results in rapid speed reductions on the interstate that can increase crash risk for inattentive drivers. A study conducted in 2014 has shown that the congested crash rates at the back of the queue on all Indiana Interstates were found to be 24 times greater than the uncongested crash rate [3]. Several states are exploring or deploying queue warning trucks to provide visual alerts to drivers approaching stopped traffic on the interstate. One such example of the deployed queue truck is shown in Figure 1. Queue trucks are deployed ahead of the work zone on Indiana Interstates. Message board signs and flashers visually alert motorists of the slow-moving traffic ahead. They are also equipped with digital alerts that could be transmitted to navigation systems. In-vehicle navigation alerts also provide an additional opportunity to improve communication to drivers of modern vehicles.

\section{Study Objective}

The use of queue trucks and in-vehicle navigation alerts can alert drivers and draw their attention as they approach slow-moving traffic due to various reasons such as crash incidents or ongoing work zone activity. Since both queue trucks and in-vehicle navigation alerts are emerging technologies, there are no best practices for their use or methods for evaluating their impact. The objective of this paper is to introduce the concept of queue trucks and navigation alerts and propose a methodology for evaluating their impact.

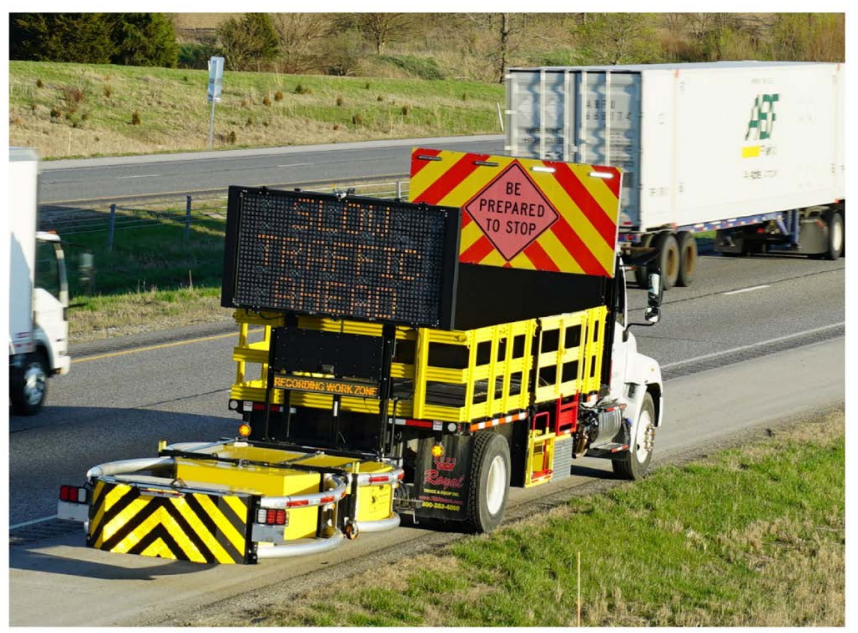

Figure 1. Queue warning truck deployed on Indiana Interstate. 


\section{Literature Review}

In the United States alone, more than 115,000 highway work zone crashes were estimated by the National Work Zone Safety Information Clearinghouse in 2019 [4], of which 762 were fatal crashes involving 842 fatalities. $24 \%$ of these work zone fatal crashes involved a rear-end collision and $31 \%$ crashes had speeding as a factor [5]. Other studies have also shown that crash rates on interstate sections with construction activity are significantly higher than those in non-work zone conditions [4] [5]. Furthermore, a study conducted in 2014 has shown that the congested crash rates at the back of the queue on all Indiana interstates were found to be 24 times greater than the uncongested crash rate [3]. Sudden speed reductions and queuing as a result of a primary crash incident, maintenance activity, or a construction work zone create hazardous conditions and a high risk for the occurrence of secondary crashes [6] [7] [8] [9]. The study conducted by Yang, Hong et al. has also shown that an additional minute increase in the incident duration will increase the likelihood of secondary crash occurrence by $1.2 \%$ [10]. Reducing these incidents, particularly the back of queue secondary crashes, continues to be an important focus for transportation agencies and other stakeholders across the country for the safety of motorists as well as construction workers.

Traditionally, fixed signs are used for communicating the presence of work zones or maintenance activities on highways. Manual on Uniform Traffic Control Devices (MUTCD) also provides guidelines on the use of temporary traffic control zone signs [11]. In the case of emergency response, signs are often incorporated onto the vehicle [12] [13] [14] [15]. The impact of these signs, flashes, message boards or digital alerts from trucks has not yet been evaluated extensively. Deployment strategies of such queue trucks are also evolving.

Technologies introduced for improving road safety are often evaluated using crash rates [16] [17] [18]. But crashes are often reported with a time lag and underreported due to a variety of reasons [19] [20] [21], including the unwillingness of involved drivers to report a crash [22]. A study conducted on 23 construction work zones that covered approximately 150 centerline miles of Indiana interstate roadway in the summer of 2019 , found that there was approximately 1 crash for every 147 hard-braking events in and around a construction site with an $R^{2}$ value of 0.85 [23]. Thus, the new commercially available hard-braking data sources provide an opportunity for agencies to follow up with mitigation measures addressing emerging problems much quicker than typical practices that rely on 3 - 5 years of crash data [24]. This study presents a methodology using these hard-braking events as a surrogate for crash incidents for impact evaluation of queue warning trucks and digital alerts.

Connected vehicle hard-braking data provides the opportunity for evaluating the impact on traffic [25] [26]. The final form of in-vehicle communication will likely change considerably over the next few years as market forces determine what type of information is directly integrated into the vehicle and what infor- 
mation is integrated via cell phones. In 2016, Li et al. compared counts from a loop detector to counts obtained from connected vehicle trajectories. This study found an overall market penetration of $1.1 \%$ with a range of $0.2 \%$ to $2.0 \%$ depending on the time of day [27]. Approximately $4.7 \%$ of the vehicles on Indiana Interstates in 2020 were fully connected to a connected vehicle provider [28]. The number of connected vehicles on the road will continue to increase. Almost $100 \%$ of vehicles travelling on interstates have at least one cell phone in the vehicle. Although there is no published data, it is reasonable to assume somewhere around $20 \%$ of vehicles on roads are running some type of in-vehicle navigation applications such as Waze, Apple, Google, Trimble, etc. [29]. This suggests a large number of vehicles driving on roadways are using advanced communication channels such as cell phones. It provides an opportunity to alert all these drivers of upcoming hazards, slow-moving or stopped traffic using the navigation alerts in combination with the visual alerts from the queue trucks. This study introduces these digital alerts and proposes a methodology for evaluating them, in combination with a queue warning truck.

\section{Data Description}

\subsection{Connected Vehicle Trajectory Data}

Commercially available anonymized trajectory data provides a unique waypoint with a reporting interval of 3 to 5 seconds. Each waypoint is associated with information of GPS location, measured on vehicle speed, heading, timestamp and an anonymous trajectory identification number. By linking individual waypoints by their trajectory identification number, a vehicle's trajectory can be obtained. Each waypoint is also associated with interstate reference points at every 0.1 miles to create the traffic speed heatmaps. One month of connected vehicle data in Indiana alone provides over 10 billion records on average.

Figure 2(a) shows the example traffic speed heatmap for Indiana Interstate-70 (I-70) in the westbound direction from mile marker (MM) 43 to MM 59 on Thursday, September 24, 2020. The horizontal axis represents the time of the day whereas the vertical axis represents the mile marker on the Interstates. The traffic speeds are color-coded by the speed bins. Crashes gathered from Indiana's online crash repository are also overlaid on top of the traffic speed heatmap. Callout $c$ points to the location of the primary crash incident that caused the slow-moving traffic shown by the pink color and secondary crash incident (callout s) at the back of the queue.

\subsection{Connected Vehicle Hard-Braking Events Data}

The hard-braking event data used in this study was made commercially available by data providers that worked directly with original equipment manufacturers (OEMs). The enhanced probe data from these connected passenger vehicles included an anonymized unique identifier with the timestamp, geolocation, speed, heading and hard-braking/acceleration as attributes. The provider of this data 


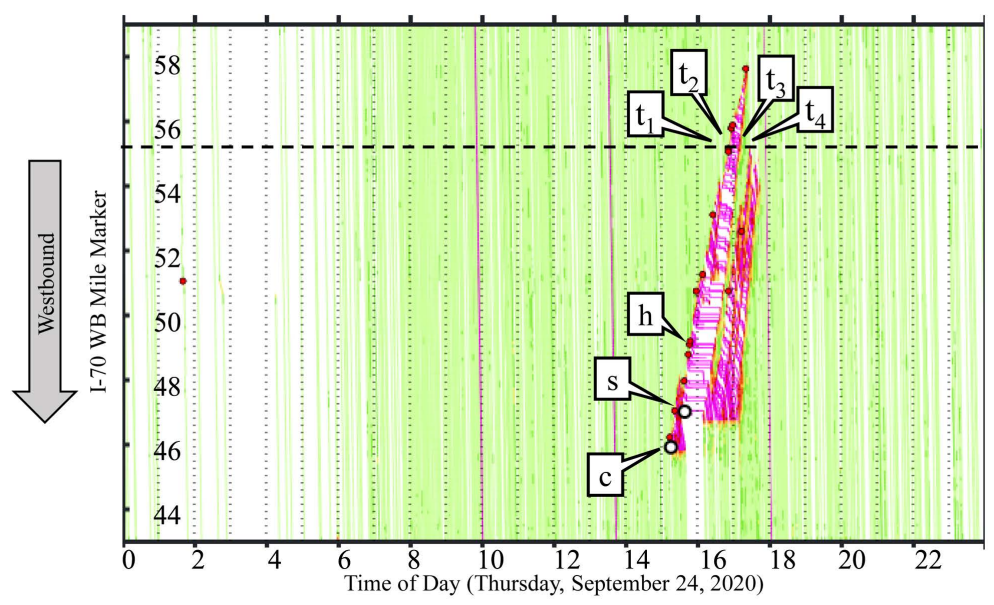

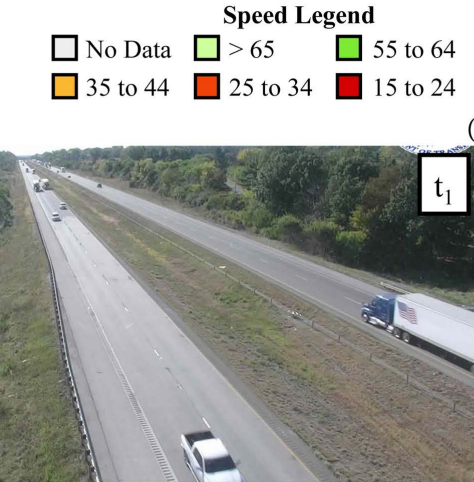

(b)

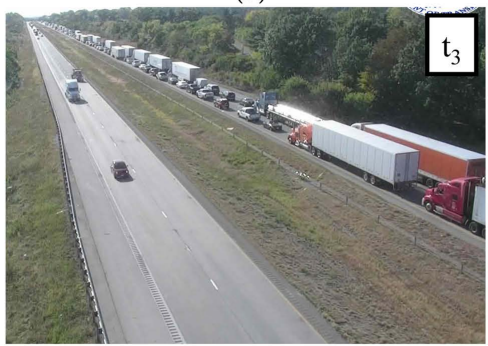

(d)

$$
\square 45 \text { to } 54
$$

$\square 0$ to 14

(a)
- Hard braking events

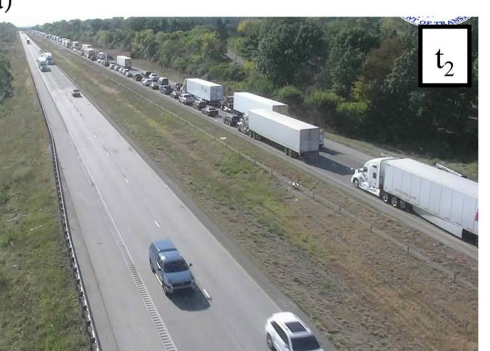

(c)

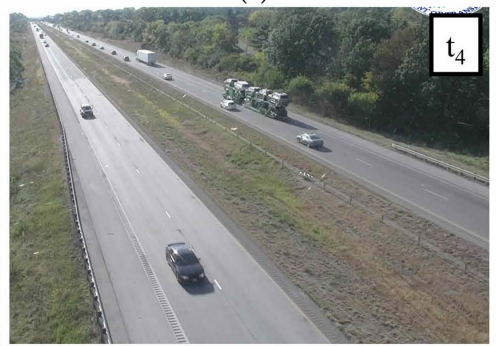

(e)

Figure 2. Traffic speed heatmap developed using trajectory data and overlaid with crashes and hard-braking events validated using the camera images. (a) Traffic speed heatmap for Indiana I-70 from MM 43 to MM 59 overlaid with crash incidents and hard-braking events; (b) Camera image at 4:53 PM; (c) Camera image at 4:56 PM; (d) Camera image at 5:08 PM; (e) Camera image at 5:14 PM.

defined hard-braking events as any vehicle decelerations with a magnitude greater than $8.76 \mathrm{ft} / \mathrm{s} 2(0.272 \mathrm{~g})$. The hard-braking events are also overlaid on the traffic speed heatmap (Figure 2(a)) shown by the red dots (callout $h$ ). It can be observed that the hard-braking events occurred at the back of the queue resulted from the earlier crash incidents.

Indiana has approximately 350 Intelligent Transportation System (ITS) cameras in its statewide surveillance system. These cameras can be used to validate and illustrate the value of connected vehicle data. The images are captured and stored every 3 minutes from these cameras. The location of the fixed ITS camera 
around mile marker 55 is shown by the black dashed line in Figure 2(a). The back of queue propagation (Figure 2(b)), congested traffic (Figure 2(c) and Figure 2(d)) and clearing traffic (Figure 2(e)) can be confirmed with camera images captured at 4:53 PM, 4:56 PM, 5:08 PM and 5:14 PM respectively (callout t1-t4).

\section{Alerts to Navigation Applications}

Queue warning trucks equipped with digital alerts send navigation alerts to drivers. Figure 3 illustrates the high-level network structure of data transfer between the queue truck on-site and communication delivery to approaching motorists via navigation application alerts. Alerts are sent from the queue trucks or any other emergency vehicle such as Hoosier Helpers to the cloud of a digital alert provider via onboard telematics. Once the alerts are transferred to the cloud, digital alerts are sent via navigations apps to motorists in the vicinity or approaching the truck. The data from the cloud is also analyzed to provide feedback to queue trucks on deployment location and strategies.

\subsection{Navigation Alert Data from Transponders}

Transponders are installed on the queue warning trucks (Figure 4(a)) and Hoosier Helpers (Figure 4(b)). It can be installed on any emergency response or driver's assistance vehicle. Any vehicle equipped with the onboard transponder device has the capability of sending alerts to the digital alert provider and then to the navigation apps such as Waze. The transponder is wired in such a way that the alerts are shown on navigation apps only when the vehicle turns on its strobe lights. Data from transponders deployed on 19 queue trucks in Indiana was used for analysis during this study.

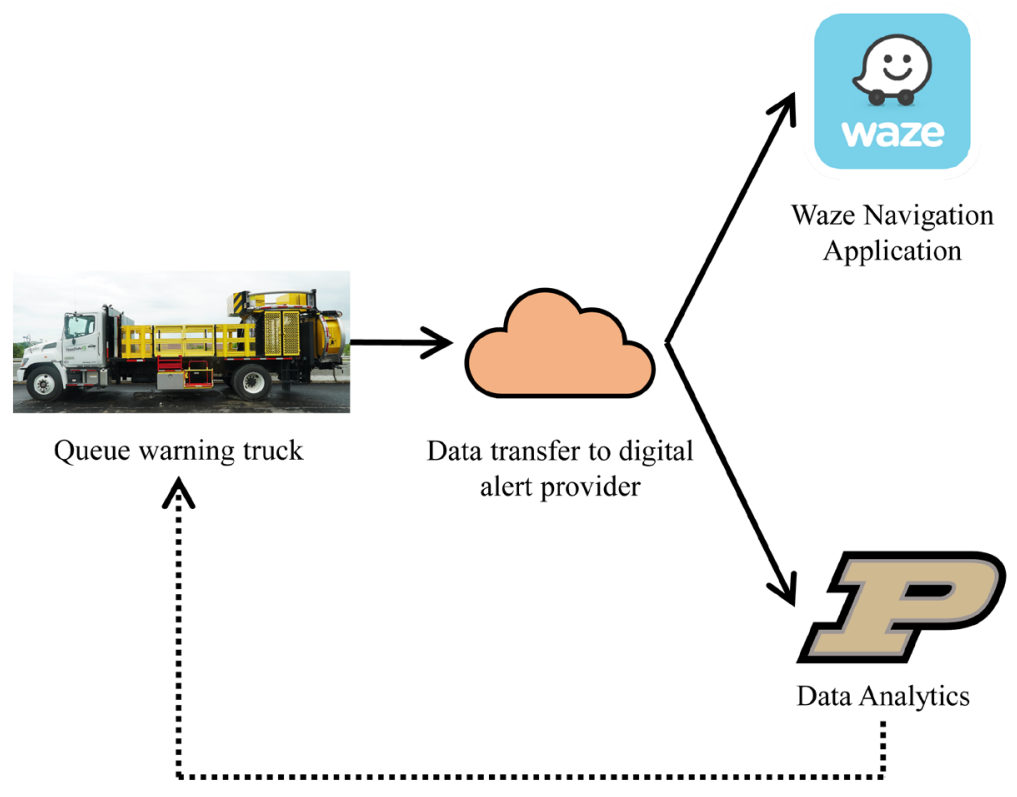

Figure 3. High-level network structure of data transfer for sending navigation alerts. 


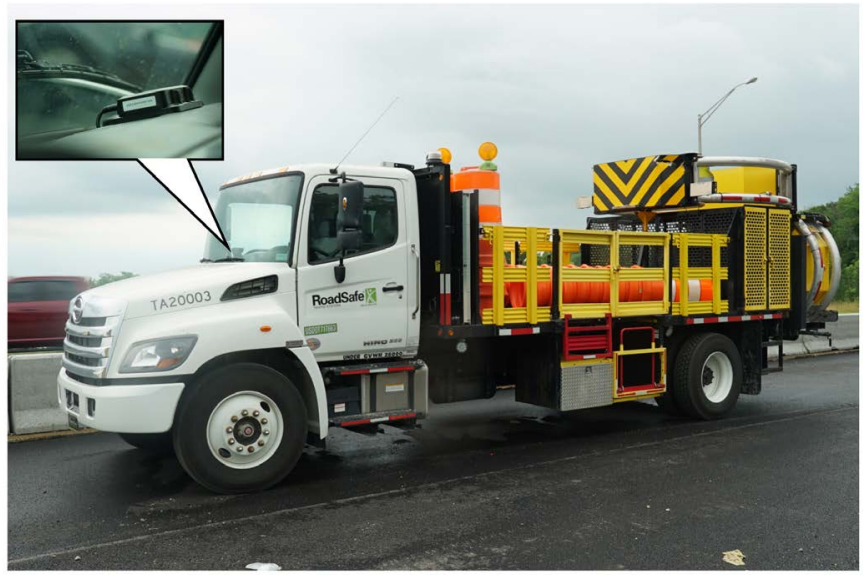

(a)

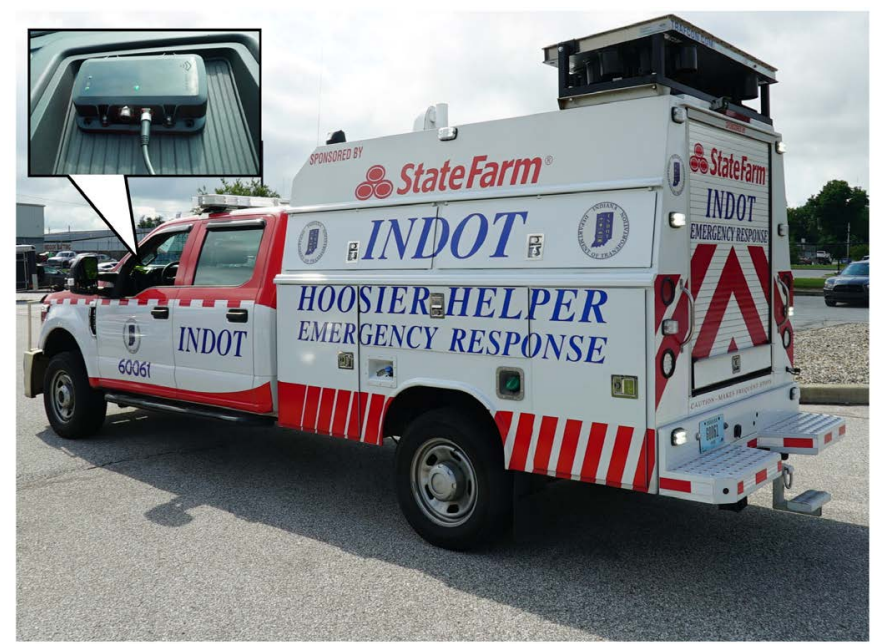

(b)

Figure 4. Transponders installed on driver's assistance and emergency response vehicles. (a) Queue Warning truck with onboard transponders; (b) Hoosier Helper with onboard transponder.

\subsection{Navigation Alert Data from Telematics Data}

Alerts generated from the vehicles, such as those as shown in Figure 4, can be generated using either agency maintained fleet telematics, or navigation alert vendor hardware. Alerts can be triggered in one of two conditions: 1) If the strobe lights are active; 2 ) Or if the vehicle is stationary or moving with a speed less than 2 miles per hour on Interstate. Currently, telematics data from 15 Indiana DOT Hoosier Helper trucks are used to send digital alerts using agency managed telematics and private sector operated queue trucks transmit alerts using navigation alert vendor supplied hardware.

A digital navigation alert example is shown in Figure 5. Callout i points to the location of Hoosier Helper responding to a crash scene on digital alert providers dashboard (Figure 5(a)), Waze navigation application (Figure 5(b)) and camera image (Figure $5(\mathrm{c})$ ). Callout $\mathrm{c}$ points to the crash incident that the response vehicle is serving to. 


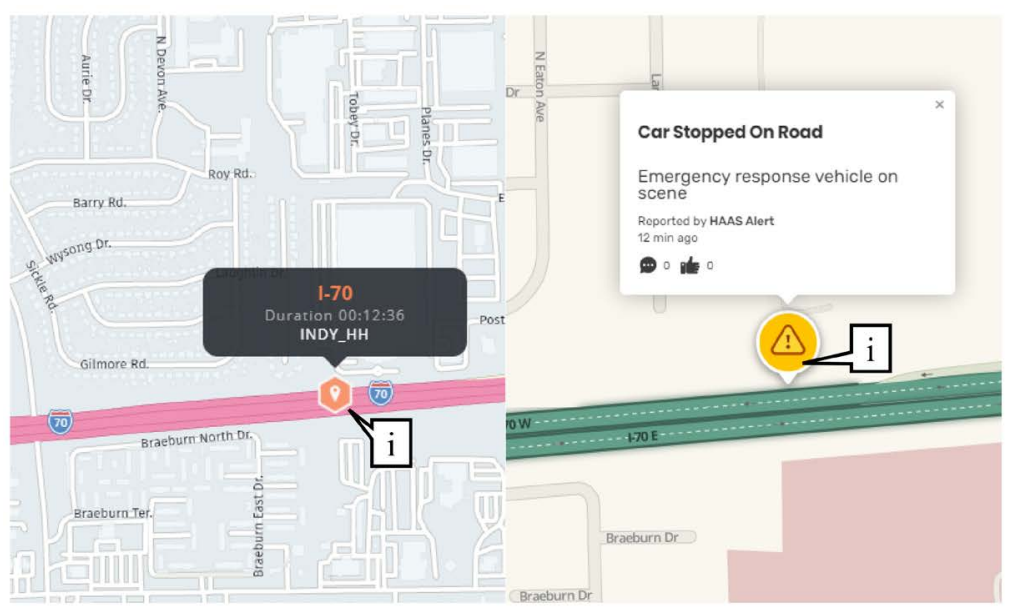

(a)

(b)

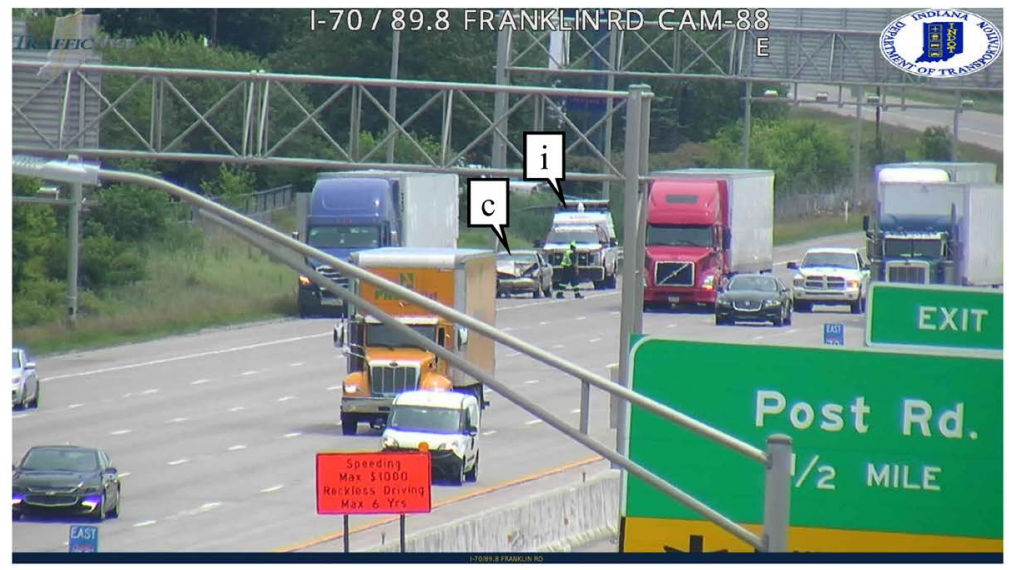

(c)

Figure 5. Alerts sent to Waze navigation application using the telematics data. (a) Digital alert provider's dashboard; (b) Alert on Waze navigation application; (c) Hoosier Helper responding to crash scene on Indiana I-70 around MM 89.8 at 12:57 PM, Thursday, June $24,2021$.

\section{Case Study Showing Impact of Queue Truck with Navigation Alerts}

A case study is presented using the traffic speed heatmap showing the impact of queue warning trucks with navigation alerts. Figure 6(a) shows the traffic speed heatmap for the stretch of Indiana I-65 from MM 168 to MM 185 in the southbound direction on Thursday, May 27, 2021. A crash incident that occurred around 6 PM resulted in a queue for roughly 3 miles and lasting over 5 hours. This queue caused 29 hard-braking events (callout h1) at the back of the queue. This incident was compared with similar traffic conditions on the previous day. Figure 6(b) shows Indiana I-65 from MM 135 to MM 155 in the same southbound direction of travel on Wednesday, May 26, 2021, during a similar time period of the day. The cause of this congestion was the ongoing work zone activity around MM 144. In this case, a queue warning truck (callout i) with an onboard transponder was present shown by the solid purple line. The queue truck 


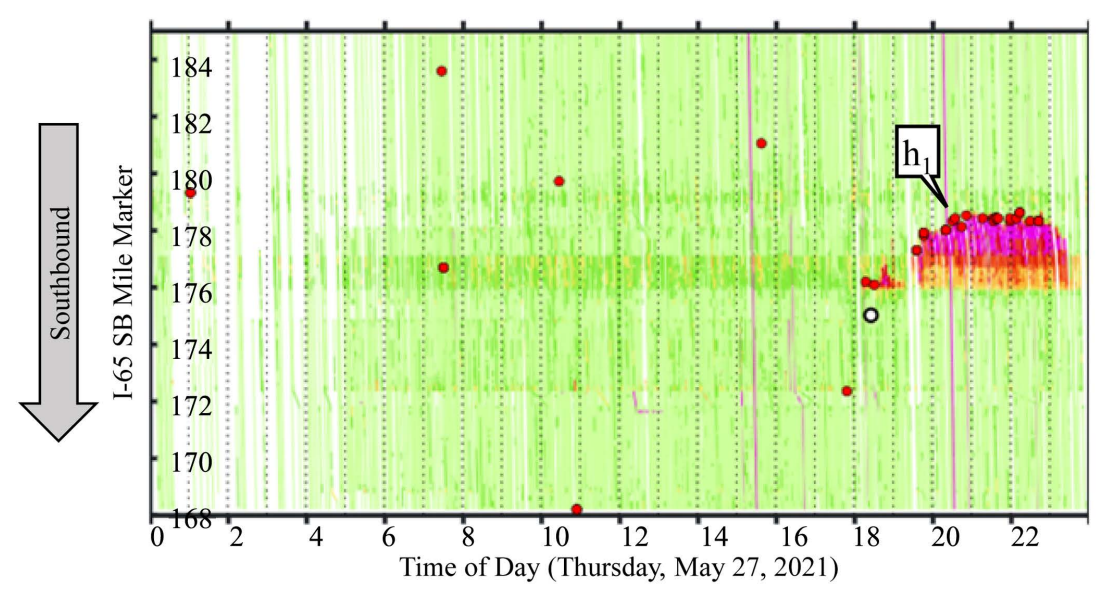

(a)

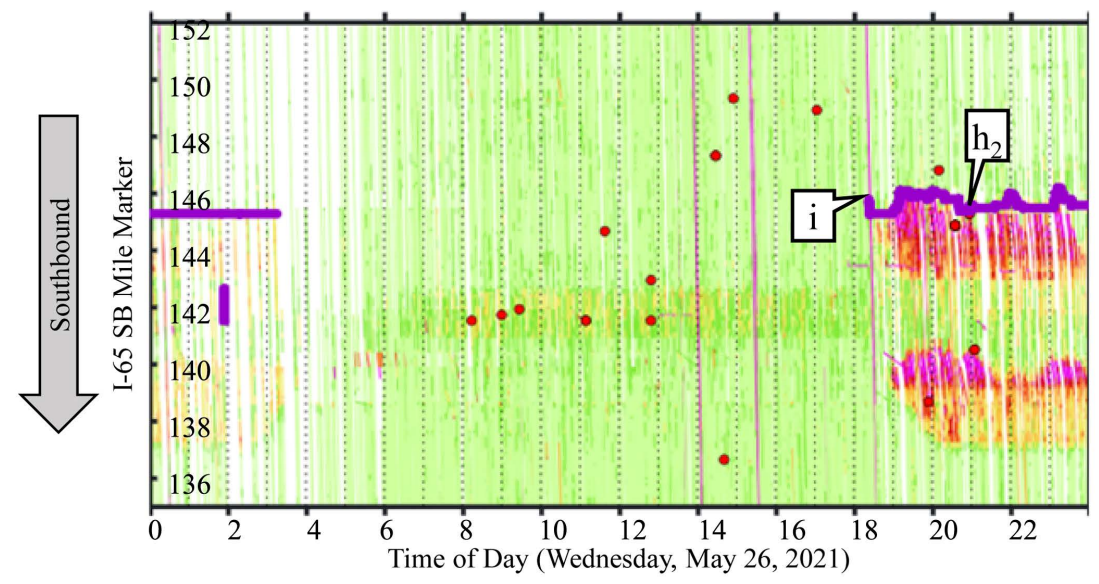

(b)

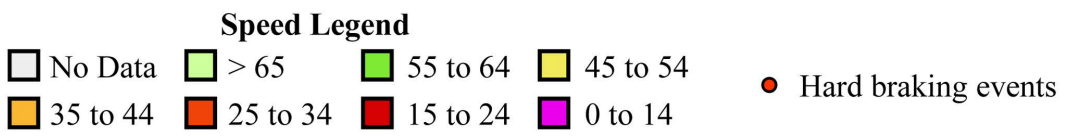

Figure 6. Comparison of hard-braking events on I-65 in southbound direction during the absence and presence of queue trucks and navigation alerts. (a) Hard-braking events during the absence of the queue truck; (b) Hard-braking events during the presence of queue truck and navigation alerts.

was alerting motorists visually as well through navigation alerts. In this case, even though the congestion started from 6:30 PM only 3 hard-braking events were observed up until midnight. Figure 7 confirms the presence of a queue warning truck (callout i) around MM 146 on I-65 from the camera image at 7:27 PM on Wednesday, May 26, 2021.

The reduction in hard-braking events from 29 to 3 was attributed to the use of queue warning trucks and digital alerts. This establishes a strong case for using queue warning trucks with on-vehicle navigation alerts to aide in reducing the number of hard-braking events and improving the safety of motorists and construction workers. 


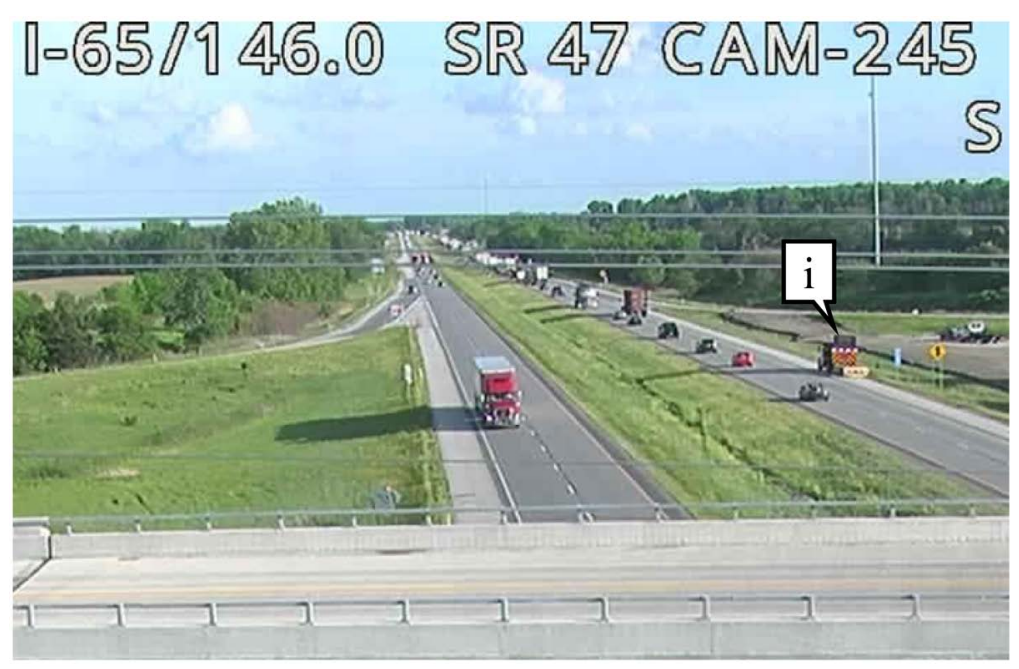

Figure 7. Camera image around MM 146 on I-65 confirming the presence of Queue warning truck at 7:27 PM on Wednesday, May 26, 2021.

\section{Longitudinal Analysis of Queue Warning Truck Impact}

This study inspected traffic speed profiles to look for queuing conditions for the months of May-July in 2021. Multiple queuing incidents on Indiana I-65 with and without the presence of queue warning trucks and navigation alerts were identified.

- Table 1 summarizes the hard-braking events during 58 hours of observed queuing with no queue trucks. 620 hard-braking events occurred in the 4195 trajectories approaching the queue i.e., $14.8 \%$ of the motorists experienced hard braking while approaching the queue.

- Table 2 summarizes the hard-braking events for 370 hours of queues when queue warning trucks were deployed with digital alerts. The trucks were deployed for ongoing work zone activity at MM 145 on I-65 during the evening hours. Only $2.6 \%$ of the trajectories experienced hard braking out of 6240 trajectories.

Comparing these two tables, hard-braking events were found to decrease approximately $80 \%$ when queue warning trucks with digital alerts were used to alert motorists of impending queues.

Figure 8 shows the scatter plot between hard-braking events and trajectories approaching queue without and during the presence of queue warning trucks and navigation alerts. Hard-braking events without and during the presence of queue warning trucks are denoted by hollow black circles and purple cross marks respectively on the scatter plot. Hard-braking events during the presence of queue trucks with digital alerts have shifted towards the lower side and grouped tightly. Linear regression estimates are shown by dotted lines for each of the groups with respective line equations and coefficient of determination $\left(R^{2}\right)$ values. Every 100 trajectories approaching the queue without any alerts will have approximately 12.73 hard-braking events (coefficient 0.1273 with $R^{2}$ of 0.7297 ) compared to only 2.66 hard-braking events if the queue warning truck with 
Table 1. Summary of hard-braking events without any queue warning trucks or navigation alerts.

\begin{tabular}{|c|c|c|c|c|c|c|c|}
\hline Date & $\begin{array}{l}\text { I-65 MM, } \\
\text { direction } \\
\text { of travel }\end{array}$ & $\begin{array}{l}\text { Start } \\
\text { time of } \\
\text { queues }\end{array}$ & $\begin{array}{c}\text { Duration } \\
\text { (hours) } \\
\text { [a] }\end{array}$ & $\begin{array}{l}\text { Number of Trajectories } \\
\text { approaching queues } \\
\text { [b] }\end{array}$ & $\begin{array}{l}\text { Hard-braking events } \\
\text { approaching queues } \\
\qquad[\mathrm{c}]\end{array}$ & $\begin{array}{c}\text { Hard-braking events } \\
\text { per hour of the queue } \\
{[\mathrm{c} / \mathrm{a}]}\end{array}$ & $\begin{array}{c}\text { Hard-braking events } \\
\text { per trajectories } \\
{[\mathrm{c} / \mathrm{b}]}\end{array}$ \\
\hline $5 / 21 / 2021$ & $165, \mathrm{SB}$ & $21: 00$ & 1 & 47 & 10 & 10 & $21.3 \%$ \\
\hline $5 / 27 / 2021$ & $176, \mathrm{SB}$ & $18: 00$ & 5 & 235 & 29 & 5.8 & $12.3 \%$ \\
\hline $5 / 28 / 2021$ & $177, \mathrm{SB}$ & $6: 30$ & 4.5 & 283 & 33 & 7.3 & $11.7 \%$ \\
\hline $6 / 2 / 2021$ & $131, \mathrm{NB}$ & $15: 00$ & 5 & 386 & 16 & 3.2 & $4.1 \%$ \\
\hline $6 / 4 / 2021$ & $125, \mathrm{SB}$ & 19:00 & 2 & 76 & 10 & 5 & $13.2 \%$ \\
\hline $6 / 10 / 2021$ & $103, \mathrm{NB}$ & $16: 00$ & 1 & 179 & 19 & 19 & $10.6 \%$ \\
\hline $6 / 10 / 2021$ & $131, \mathrm{SB}$ & $16: 00$ & 1 & 149 & 15 & 15 & $10.1 \%$ \\
\hline $6 / 11 / 2021$ & $178, \mathrm{NB}$ & $13: 30$ & 2.5 & 131 & 33 & 13.2 & $25.2 \%$ \\
\hline $6 / 11 / 2021$ & $190, \mathrm{NB}$ & $12: 30$ & 8 & 91 & 55 & 6.9 & $60.4 \%$ \\
\hline $6 / 11 / 2021$ & $189, \mathrm{SB}$ & $12: 30$ & 6 & 407 & 41 & 6.8 & $10.1 \%$ \\
\hline $6 / 18 / 2021$ & $128, \mathrm{SB}$ & $18: 00$ & 1.5 & 152 & 14 & 9.3 & $9.2 \%$ \\
\hline $6 / 25 / 2021$ & $158, \mathrm{SB}$ & $14: 00$ & 2.5 & 219 & 37 & 14.8 & $16.9 \%$ \\
\hline $7 / 1 / 2021$ & $151, \mathrm{NB}$ & $13: 00$ & 1.5 & 138 & 21 & 14 & $15.2 \%$ \\
\hline $7 / 1 / 2021$ & $190, \mathrm{NB}$ & $14: 30$ & 1.5 & 154 & 33 & 22 & $21.4 \%$ \\
\hline $7 / 2 / 2021$ & $161, \mathrm{NB}$ & $17: 30$ & 1 & 110 & 46 & 46 & $41.8 \%$ \\
\hline $7 / 2 / 2021$ & $166, \mathrm{SB}$ & $15: 00$ & 2 & 172 & 26 & 13 & $15.1 \%$ \\
\hline $7 / 5 / 2021$ & $177, \mathrm{NB}$ & $12: 30$ & 2 & 206 & 45 & 22.5 & $21.8 \%$ \\
\hline $7 / 5 / 2021$ & $176, \mathrm{SB}$ & $12: 30$ & 3 & 238 & 53 & 17.7 & $22.3 \%$ \\
\hline $7 / 9 / 2021$ & $176, \mathrm{NB}$ & $14: 00$ & 2 & 305 & 41 & 20.5 & $13.4 \%$ \\
\hline $7 / 9 / 2021$ & $181, \mathrm{NB}$ & $19: 00$ & 2 & 106 & 13 & 6.5 & $12.3 \%$ \\
\hline $7 / 16 / 2021$ & $134, \mathrm{SB}$ & $14: 00$ & 1.5 & 220 & 16 & 10.7 & $7.3 \%$ \\
\hline \multirow[t]{2}{*}{$7 / 23 / 2021$} & $167, \mathrm{SB}$ & $13: 00$ & 1.5 & 191 & 14 & 9.3 & $7.3 \%$ \\
\hline & Total & & 58 & 4195 & 620 & 10.7 & $14.8 \%$ \\
\hline
\end{tabular}

Table 2. Summary of hard-braking events during the presence of queue warning trucks and navigation alerts.

\begin{tabular}{|c|c|c|c|c|c|c|c|}
\hline Date & $\begin{array}{l}\text { I-65 MM, } \\
\text { direction } \\
\text { of travel }\end{array}$ & $\begin{array}{l}\text { Start } \\
\text { time of } \\
\text { queues }\end{array}$ & $\begin{array}{c}\text { Duration } \\
\text { (hours) } \\
\text { [a] }\end{array}$ & $\begin{array}{c}\text { Number of Trajectories } \\
\text { approaching queues } \\
{[\mathrm{b}]}\end{array}$ & $\begin{array}{c}\text { Hard-braking events } \\
\text { approaching queues } \\
{[\mathrm{c}]}\end{array}$ & $\begin{array}{c}\text { Hard-braking events } \\
\text { per hour of the queue } \\
{[\text { [c/a] }}\end{array}$ & $\begin{array}{c}\text { Hard-braking events } \\
\text { per trajectories } \\
{[\mathrm{c} / \mathrm{b}]}\end{array}$ \\
\hline $5 / 18 / 2021$ & $144, \mathrm{NB}$ & $18: 30$ & 10.5 & 126 & 1 & 0.1 & $0.8 \%$ \\
\hline $5 / 19 / 2021$ & $144, \mathrm{NB}$ & $18: 30$ & 10 & 134 & 2 & 0.2 & $1.5 \%$ \\
\hline $5 / 20 / 2021$ & $144, \mathrm{NB}$ & 19:00 & 10 & 134 & 9 & 0.9 & $6.7 \%$ \\
\hline $5 / 21 / 2021$ & $144, \mathrm{SB}$ & $19: 30$ & 9.5 & 178 & 5 & 0.5 & $2.8 \%$ \\
\hline $5 / 24 / 2021$ & 144, SB & $18: 30$ & 11 & 147 & 5 & 0.5 & $3.4 \%$ \\
\hline $5 / 25 / 2021$ & 144, SB & 19:00 & 8.5 & 123 & 5 & 0.6 & $4.1 \%$ \\
\hline $5 / 26 / 2021$ & 144, SB & $18: 30$ & 11 & 180 & 4 & 0.4 & $2.2 \%$ \\
\hline $6 / 1 / 2021$ & $144, \mathrm{SB}$ & $18: 30$ & 9.5 & 123 & 2 & 0.2 & $1.6 \%$ \\
\hline
\end{tabular}




\section{Continued}

\begin{tabular}{|c|c|c|c|c|c|c|c|}
\hline $6 / 3 / 2021$ & 144, SB & $18: 30$ & 11.5 & 195 & 6 & 0.5 & $3.1 \%$ \\
\hline $6 / 4 / 2021$ & $145, \mathrm{SB}$ & 19:00 & 11 & 310 & 4 & 0.4 & $1.3 \%$ \\
\hline $6 / 7 / 2021$ & $144, \mathrm{NB}$ & $20: 00$ & 10 & 110 & 4 & 0.4 & $3.6 \%$ \\
\hline $6 / 7 / 2021$ & $142, \mathrm{SB}$ & 19:00 & 11 & 129 & 3 & 0.3 & $2.3 \%$ \\
\hline $6 / 8 / 2021$ & $144, \mathrm{NB}$ & 19:00 & 6 & 95 & 0 & 0.0 & $0.0 \%$ \\
\hline $6 / 11 / 2021$ & $144, \mathrm{NB}$ & $20: 00$ & 9 & 150 & 4 & 0.4 & $2.7 \%$ \\
\hline $6 / 21 / 2021$ & $146, \mathrm{NB}$ & 19:00 & 9 & 146 & 3 & 0.3 & $2.1 \%$ \\
\hline $6 / 22 / 2021$ & $146, \mathrm{NB}$ & $20: 00$ & 9 & 101 & 4 & 0.4 & $4.0 \%$ \\
\hline $6 / 23 / 2021$ & $146, \mathrm{NB}$ & $22: 00$ & 7 & 47 & 0 & 0.0 & $0.0 \%$ \\
\hline $6 / 28 / 2021$ & 145, SB & $20: 30$ & 8 & 108 & 0 & 0.0 & $0.0 \%$ \\
\hline $6 / 29 / 2021$ & $145, \mathrm{NB}$ & $20: 00$ & 5 & 77 & 2 & 0.4 & $2.6 \%$ \\
\hline $7 / 1 / 2021$ & 144, SB & 19:00 & 10.5 & 279 & 9 & 0.9 & $3.2 \%$ \\
\hline $7 / 8 / 2021$ & $146, \mathrm{NB}$ & 19:00 & 8 & 178 & 4 & 0.5 & $2.2 \%$ \\
\hline $7 / 8 / 2021$ & 144, SB & 19:00 & 11 & 204 & 5 & 0.5 & $2.5 \%$ \\
\hline $7 / 9 / 2021$ & $147, \mathrm{NB}$ & $20: 00$ & 8 & 182 & 4 & 0.5 & $2.2 \%$ \\
\hline $7 / 9 / 2021$ & 144, SB & $20: 00$ & 8 & 208 & 8 & 1.0 & $3.8 \%$ \\
\hline $7 / 12 / 2021$ & $147, \mathrm{NB}$ & 19:00 & 9 & 145 & 0 & 0.0 & $0.0 \%$ \\
\hline $7 / 12 / 2021$ & $144, \mathrm{SB}$ & $21: 00$ & 7 & 82 & 0 & 0.0 & $0.0 \%$ \\
\hline $7 / 14 / 2021$ & $147, \mathrm{NB}$ & 19:00 & 9.5 & 142 & 1 & 0.1 & $0.7 \%$ \\
\hline $7 / 19 / 2021$ & $147, \mathrm{NB}$ & $19: 00$ & 10.5 & 150 & 5 & 0.5 & $3.3 \%$ \\
\hline $7 / 19 / 2021$ & 146, SB & $18: 30$ & 11.5 & 193 & 4 & 0.3 & $2.1 \%$ \\
\hline $7 / 20 / 2021$ & $146, \mathrm{NB}$ & 19:00 & 6 & 89 & 1 & 0.2 & $1.1 \%$ \\
\hline $7 / 20 / 2021$ & 146, SB & 19:00 & 10.5 & 167 & 5 & 0.5 & $3.0 \%$ \\
\hline $7 / 20 / 2021$ & $141, \mathrm{SB}$ & $20: 00$ & 6.5 & 122 & 4 & 0.6 & $3.3 \%$ \\
\hline $7 / 21 / 2021$ & $147, \mathrm{NB}$ & 19:00 & 10 & 140 & 4 & 0.4 & $2.9 \%$ \\
\hline $7 / 21 / 2021$ & $147, \mathrm{SB}$ & $19: 30$ & 9 & 174 & 4 & 0.4 & $2.3 \%$ \\
\hline $7 / 21 / 2021$ & $141, \mathrm{SB}$ & $19: 30$ & 4 & 155 & 5 & 1.3 & $3.2 \%$ \\
\hline $7 / 22 / 2021$ & $145, \mathrm{NB}$ & $18: 30$ & 11 & 195 & 11 & 1.0 & $5.6 \%$ \\
\hline $7 / 22 / 2021$ & 146, SB & $19: 30$ & 10.5 & 240 & 8 & 0.8 & $3.3 \%$ \\
\hline $7 / 23 / 2021$ & $146, \mathrm{NB}$ & $20: 00$ & 7 & 150 & 5 & 0.7 & $3.3 \%$ \\
\hline $7 / 23 / 2021$ & 146, SB & $20: 30$ & 9 & 182 & 4 & 0.4 & $2.2 \%$ \\
\hline $7 / 26 / 2021$ & $146, \mathrm{SB}$ & $19: 00$ & 10 & 126 & 4 & 0.4 & $3.2 \%$ \\
\hline \multirow[t]{2}{*}{$7 / 27 / 2021$} & $146, \mathrm{SB}$ & 19:00 & 7 & 124 & 5 & 0.7 & $4.0 \%$ \\
\hline & Total & & 370 & 6240 & 163 & 0.44 & $2.6 \%$ \\
\hline
\end{tabular}

alerts was present (coefficient 0.0266 with $R^{2}$ of 0.8162 ). A high $R^{2}$ value suggests the linear trendline is able to explain most of the dataset. Past studies have indicated a strong relationship between hard-braking and crashes [23]. This clear reduction in hard-braking events for queue warning trucks with alerts is anticipated to reduce crashes by a similar proportion. 


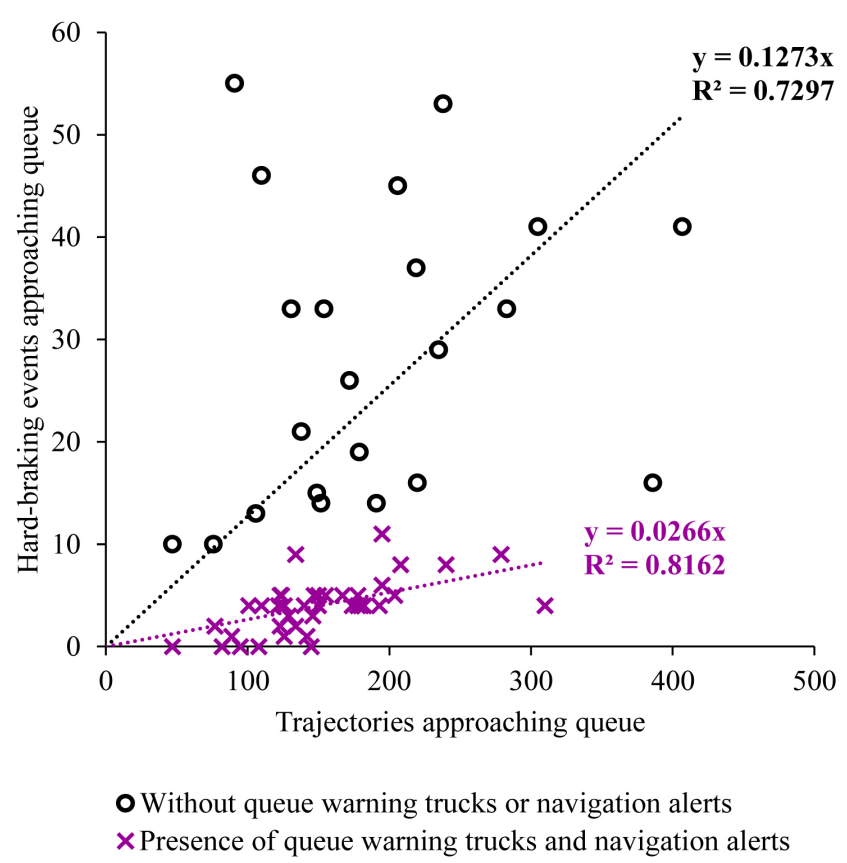

Figure 8. Scatter plot comparing the hard-braking events and trajectories approaching queues without and during the presence of queue warning trucks and navigation alerts.

\section{Conclusions}

Several states are exploring or deploying the queue warning trucks to alert motorists approaching stopped or slow-moving traffic and provide them with in-vehicle navigation alerts. The final form of connected vehicles will likely change considerably over the next few years as market forces determine what type of information is directly integrated into the vehicle and what information is integrated via cell phones. In-vehicle notification will be complementing roadside signs moving forward. A methodology was described using connected vehicle hard-braking events for evaluating the impact of these queue trucks.

Navigation alerts can be sent by using agency maintained fleet telematics, or navigation alert vendor hardware. A case study on I-65 showed the reduction of hard-braking events from 29 to 3 while using the queue warning truck with digital alerts. This paper reports on the novel use of connected vehicle data to assess the impact of queue warning trucks. A longitudinal comparison of queueing for 370 hours with the presence of trucks and 58 hours without trucks was conducted during the months of May-July in 2021. Hard-braking events were found to decrease approximately $80 \%$ when queue warning trucks were used to alert motorists of impending queues. Encouraging results support the deployment of queue trucks and integration of digital alerts for reducing the risks of secondary crashes on Interstates.

\section{Acknowledgements}

Trajectory data for September 20, 2020 and weekdays between May 18-July 27, 2021 used in this study was provided by Wejo Data Services, Inc. Navigation 
alert vendor and digital alerts data used during this study was provided by HAAS Alert. The contents of this study reflect the views of the authors, who are responsible for the facts and the accuracy of the data presented herein and do not necessarily reflect the official views or policies of the sponsoring organizations. These contents do not constitute a standard, specification, or regulation.

\section{Conflicts of Interest}

The authors declare no conflicts of interest regarding the publication of this paper.

\section{References}

[1] Tennessee Department of Transportation (2021) Protect the Queue. https://www.tn.gov/tdot/traffic-operations-division/transportation-management-off ice/protect-the-queue.html

[2] Indiana Department of Transportation (2020) Protect the Queue: INDOT's Queue Awareness Program.

https://www.in.gov/indot/safety/protect-the-queue-indots-queue-awareness-progra $\mathrm{m} /$

[3] Mekker, M.M., Remias, S.M., McNamara, M.L. and Bullock, D.M. (2020) Characterizing Interstate Crash Rates Based on Traffic Congestion Using Probe Vehicle Data. JTRP Affiliated Reports, Paper No. 31. https://doi.org/10.5703/1288284317119

[4] National Work Zone Safety Information Clearinghouse (2019) National Estimates of Total and Injury Work Zone Crashes

https://www.workzonesafety.org/Crash-Information/Work-Zone-Injuries-Injury-Pr operty-Damage-Crashes/

[5] U.S. Department of Labor, Bureau of Labor Statistics, in Cooprtation with State, New York City, District of Columbia (2019) 2018 and 2019 Census of Fatal Occupational Injuries. Bureau of Labor Statistics (BLS), USA, Publication No. USDL-20-2265. https://www.bls.gov/news.release/pdf/cfoi.pdf

[6] Yang, H., Bartin, B. and Ozbay, K. (2014) Mining the Characteristics of Secondary Crashes on Highways. Journal of Transportation Engineering, 140, Article ID: 04013024. https://doi.org/10.1061/(ASCE)TE.1943-5436.0000646

[7] Giuliano, G. (1989) Incident Characteristics, Frequency, and Duration on a High Volume Urban Freeway. Transportation Research Part A: General, 23, 387-396. https://doi.org/10.1016/0191-2607(89)90086-1

[8] Garber, N.J. and Zhao, M. (2002) Distribution and Characteristics of Crashes at Different Work Zone Locations in Virginia. Transportation Research Record, 1794, 19-28. https://doi.org/10.3141/1794-03

[9] Khattak, A.J., Khattak, A.J. and Council, F.M. (2002) Effects of Work Zone Presence on Injury and Non-Injury Crashes. Accident Analysis and Prevention, 34, 19-29. https://doi.org/10.1016/S0001-4575(00)00099-3

[10] Yang, H., Ozbay, K. and Xie, K. (2014) Assessing the Risk of Secondary Crashes on Highways. Journal of Safety Research, 49, 143.e1-149.

https://doi.org/10.1016/j.jsr.2014.03.007

[11] Federal Highway Administration (2021) Manual on Uniform Traffic Control Devices. https://mutcd.fhwa.dot.gov/pdfs/millennium/pr2/6fr2.pdf

[12] Indiana LTAP and Ohio Department of Transportation (2017) Concise Handbook 
for Temporary Traffic Control-Construction, Maintenancem and Utility Operations. Indiana Local Technical Assistance Program (LTAP) Publications, West Lafayette, Paper No. 116. https://docs.lib.purdue.edu/inltappubs/116

[13] Pourfalatoun, S. and Miller, E.E. (2021) User Perceptions of Automated TruckMounted Attenuators: Implications on Work Zone Safety. Traffic Injury Prevention, 22, 413-418.

[14] Kivi, A. and Olidis, C. (2015) Challenges in Ensuring Worker Safety in Active Roadway Work Zones. Conference of the Transportation Association of Canada, Charlottetown, 27-30 September 2015, Article No. 416

[15] Cottrell, B.H. (2015) Investigation of Truck Mounted Attenuator (TMA) Crashes in Work Zones in Virginia. Virginia Transportation Research Council, Charlottesville, 45 p. http://www.virginiadot.org/vtrc/main/online_reports/pdf/16-r7.pdf https://trid.trb.org/view/1396173

[16] Soole, D.W., Watson, B.C. and Fleiter, J.J. (2013) Effects of Average Speed Enforcement on Speed Compliance and Crashes: A Review of the Literature. Accident Analysis and Prevention, 54, 46-56. https://doi.org/10.1016/j.aap.2013.01.018

[17] Carnis, L. and Blais, E. (2013) An Assessment of the Safety Effects of the French Speed Camera Program. Accident Analysis and Prevention, 51, 301-309. https://doi.org/10.1016/j.aap.2012.11.022

[18] Aarts, L. and Van Schagen, I. (2006) Driving Speed and the Risk of Road Crashes: A Review. Accident Analysis and Prevention, 38, 215-224.

https://doi.org/10.1016/j.aap.2005.07.004

[19] Yamamoto, T., Hashiji, J. and Shankar, V.N. (2008) Underreporting in Traffic Accident Data, Bias in Parameters and the Structure of Injury Severity Models. Accident Analysis and Prevention, 40, 1320-1329. https://doi.org/10.1016/j.aap.2007.10.016

[20] Janstrup, K.H., Kaplan, S., Hels, T., Lauritsen, J. and Prato, C.G. (2016) Understanding Traffic Crash Under-Reporting: Linking Police and Medical Records to Individual and Crash Characteristics. Traffic Injury Prevention, 17, 580-584.

[21] Tarko, A. (2019) Measuring Road Safety with Surrogate Events. 1st Edition, Elsevier, Amsterdam, 1-252. https://doi.org/10.1016/C2016-0-00255-3

[22] Blincoe, L.J., Seay, A.G., Zaloshnja, E., Miller, T.R., Romano, E.O., Luchter, S. and Spicer, R.S. (2000) The Economic Impact of Motor Vehicle Crashes, 2000. U.S. National Highway Traffic Safety Administration, Washington DC.

https://rosap.ntl.bts.gov/view/dot/15504

[23] Desai, J., Li, H., Mathew, J.K., Cheng, Y.T., Habib, A. and Bullock, D.M. (2021) Correlating Hard-Braking Activity with Crash Occurrences on Interstate Construction Projects in Indiana. Journal of Big Data Analytics in Transportation, 3, 27-41. https://doi.org/10.1007/s42421-020-00024-x

[24] Hunter, M., Saldivar-Carranza, E., Desai, J., Mathew, J.K., Li, H. and Bullock, D.M. (2021) A Proactive Approach to Evaluating Intersection Safety Using Hard-Braking Data. Journal of Big Data Analytics in Transportation, 3, 81-94. https://doi.org/10.1007/s42421-021-00039-y

[25] Sakhare, R.S., Desai, J.C., Mathew, J.K., McGregor, J.D. and Bullock, D.M. (2021) Evaluation of the Impact of Presence Lighting and Digital Speed Limit Trailers on Interstate Speeds in Indiana Work Zones. Journal of Transportation Technologies, 11, 157-167. https://doi.org/10.4236/jtts.2021.112010

[26] Mathew, J.K., Desai, J.C., Sakhare, R.S., Kim, W., Li, H. and Bullock, D.M. (2021) Big Data Application for Managing Roadways. ITE Journal, 91, 28-35. 
https://www.nxtbook.com/ygsreprints/ITE/ite-journal-february-2021/index.php\#/p 128

[27] Li., H., Day, C.M. and Bullock, D.M. (2016) Virtual Detection at Intersections Using Connected Vehicle Trajectory Data. Proceedings of IEEE Conference on Intelligent Transportation Systems, Rio de Janeiro, 1-4 November 2016, 2571-2576. https://doi.org/10.1109/ITSC.2016.7795969

[28] Hunter, M., Mathew, J.K., Cox, E., Blackwell, M. and Bullock, D.M. (2021) Estimation of Connected Vehicle Penetration Rate on Indiana Roadways. JTRP Affiliated Reports, Paper No. 37. https://doi.org/10.5703/1288284317343

[29] Holan, M. (2020, May 6) Trimble and Purdue University Collaborate to Improve Highway Work Zone Safety.

https://newsline.artba.org/2020/05/06/trimble-and-purdue-university-collaborate-t o-improve-highway-work-zone-safety/ 